\title{
Endometrial Vascularity: Its Relation to Implantation Rates
}

Chaitanya Nagori, Sonal Panchal

\section{ABSTRACT}

Aim: The aim of this study was to find out if endometrial vascularity can be used as a predictive factor for implantation.

Materials and methods: This is a retrospective study of 500 ovum donation-embryo transfer cycles, with basal S FSH $>25$. Those with endometrial thickness of $>8 \mathrm{~mm}$ with intact junctional zone and uterine artery $\mathrm{PI}<3.2$ were taken for embryo-transfer. Vaginal micronized progesterone was started from the day of ovum pick up of the ovum donor. Two fresh grade 1, 4-6 cell embryos, were transferred on day 3. Progesterone support was continued till the day of $\beta$-hCG. $\beta$-hCG was checked in all patients followed by USG 2 weeks later. Results were observed for four groups, depending on vascularity zones 1, 2, 3, 4. ${ }^{2}$ Follow-up with ultrasound was done till 8 weeks for ongoing pregnancy.

Results: The biochemical pregnancy rates and ultrasound evidenced pregnancy rates were very high when vascularity was seen in zone 3 and 4 of endometrium with low abortion rates.

Conclusion: We believe that endometrial vascularity is an important parameter to assess the implantation potential of the endometrium.

Keywords: Endometrial vascularity, Implantation rates.

How to cite this article: Nagori C, Panchal S. Endometrial Vascularity: Its Relation to Implantation Rates. Int J Infertility Fetal Med 2012;3(2):48-50.

\section{Source of support: Nil}

Conflict of interest: None declared

\section{MATERIALS AND METHODS}

This is a retrospective study of 500 ovum donation-embryo transfer cycles, enrolled at our center from January 2003 to December 2010. All these cycles were egg sharing cycles or dedicated donor cycles. All these patients had ovarian failure and was confirmed by basal S FSH levels $>25$. Oral Ethinyl estradiol given to all patients for endometrial preparation. The protocol followed was $2 \mathrm{mg}$ once a day for 4 days, followed by $2 \mathrm{mg}$, twice a day for another 4 days, followed by $2 \mathrm{mg}$ thrice a day till the day of hCG to the donor. Endometrial thickness, endometrio-myometrial junction and endometrial morphology were assessed for on B mode scan of endometrium. Scans were done by single operator with transvaginal volume probe 5 to $9 \mathrm{MHz}$, on Voluson 730 Expert (GE Medical Systems). Those with endometrial thickness $<8 \mathrm{~mm}$, interrupted or irregular endometrio-myometrial junction and those with homogenous

Date of Received: 28-06-12

Date of Acceptance: 19-07-12

Date of Publication: May 2012 (non-multilayered-grade C) ${ }^{1}$ endometrium were excluded from the study. Endometrium was graded as grade $\mathrm{A}$ (Fig. 1) when it was multilayered with low level echogenecities in intervening area, grade B (Fig. 2) when it was multilayered with hypoechoic intervening area and grade $\mathrm{C}$ when it was isoechoic homogenous ${ }^{1}$ (Fig. 3). Color and pulse Doppler studies of endometrium and uterine artery was done for the patients that were included in the study. Color Doppler settings were set with PRF 0.3 and lowest wall filter. Pulse Doppler settings for uterine artery were set at PRF 0.9. Patients that showed uterine artery PI of $>3.2$ were further excluded from the study. After these exclusions, the final number of patients in the study was 463. Vaginal micronized progesterone $400 \mathrm{mg}$ thrice a day was started from the day of ovum pick up of the ovum donor. Embryo-transfer was done on day 3. Two fresh grade 1, 4-6 cell embryos, were transferred in all. Progesterone

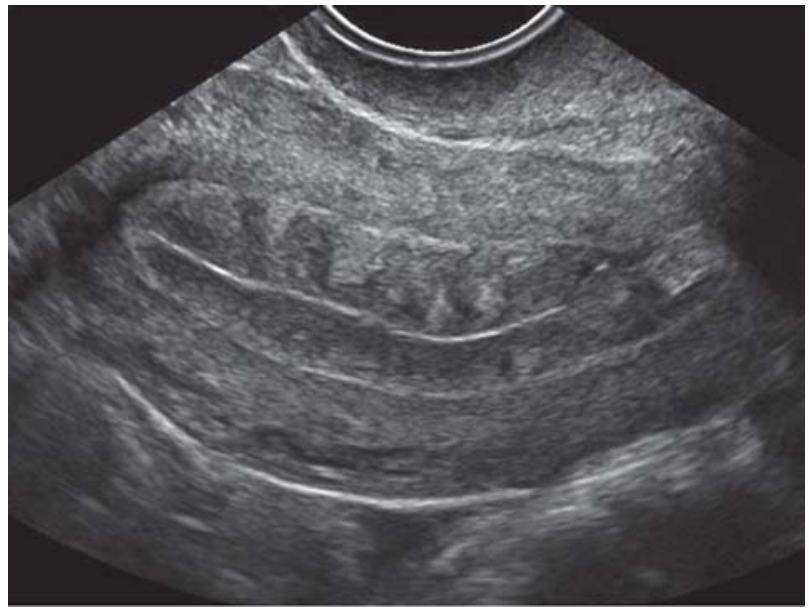

Fig. 1: Endometrial morphology: Grade A

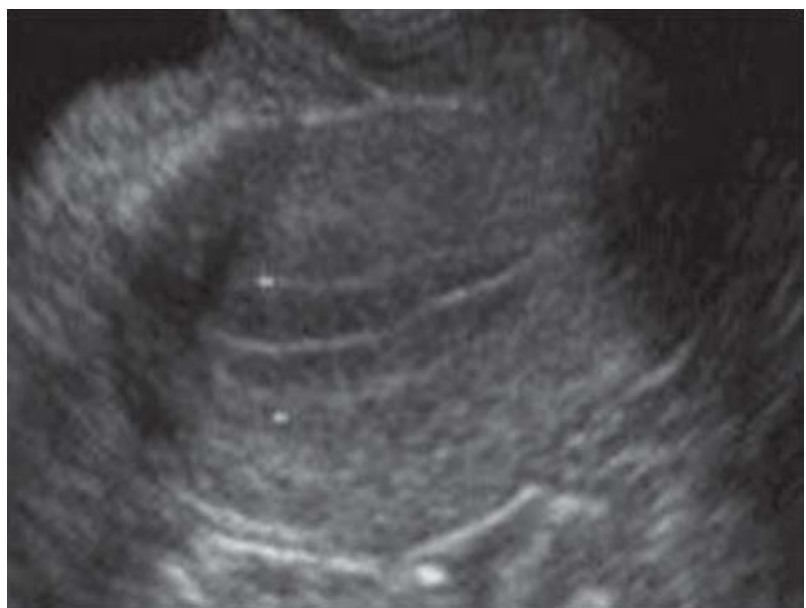

Fig. 2: Endometrial morphology: Grade B 
support was continued till the day of $\beta$-hCG, that was day 12 after transfer. Positive pregnancy test, that is $\beta$-hCG $>10$, was the primary desired result. Presence of gestational sac in endometrial cavity on ultrasound done after 2 weeks of $\beta$-hCG was the final desired result. Frequency of primary and final desired results were calculated for four groups, depending on vascularity zones $1,2,3,4 .^{2}$ When blood vessels reached the hypoechoic endometrio-myometrial junction, it was graded as zone 1 vascularity (Fig. 4), when it reached the outer hyperechoic line of endometrium, it was zone 2 vascularity (Fig. 5), when it reached the intervening hypoechoic area it was known as zone 3 (Fig. 6) vascularity and when vessels reached the central echogenic line, it was known as zone 4 vascularity (Fig. 7). Follow-up with ultrasound was done till 8 weeks for ongoing pregnancy.

\section{RESULTS}

Table 1 shows the numbers of the patients with vascularity in zone 1,2 , 3 and 4 , number of patients with $+\beta$-hCG results in each group, number of patients with ultrasound evidence of pregnancy in each group and number of abortions/failed pregnancies in each group.

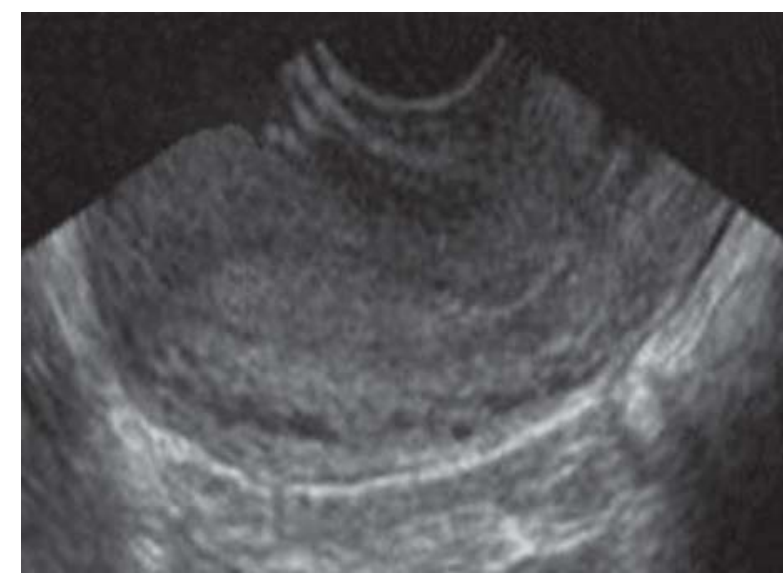

Fig. 3: Endometrial morphology: Grade C

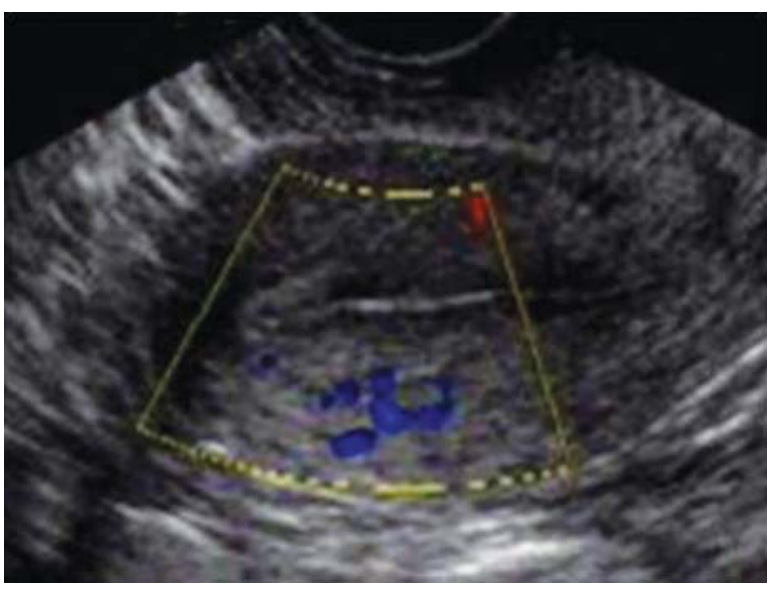

Fig. 4: Endometrial vascularity: Zone 1
Table 2 shows the distribution of patient population for vascularity in zone 1, 2, 3 and 4 of the endometrium. The second row in Table 2 shows chemical pregnancy rate (in percentage), in each group, row 3 shows how many percentage of patients with vascularity in a particular vascularity zone had an ultrasound evidence of pregnancy. The last row in Table 2 shows the abortion rates in each group.

\section{DISCUSSION}

Implantation is the weakest link for the success of any ART procedure. Several workers have presented several parameters and assessment techniques to assess the implantation potential of the endometrium. Intact endometrio-myometrial junction and thickness of minimum $8 \mathrm{~mm}$ have been the most established ones. Smith et $\mathrm{al}^{1}$ have graded the endometrial morphology into grade $\mathrm{A}, \mathrm{B}$, and $\mathrm{C}$. Gonen and Casper $^{3}$ have classified the endometrial morphology into type A, B and C. Both have found better implantation rates when the endometrium was multilayered with echogenecities in the hypoechoic areas in between the lines.

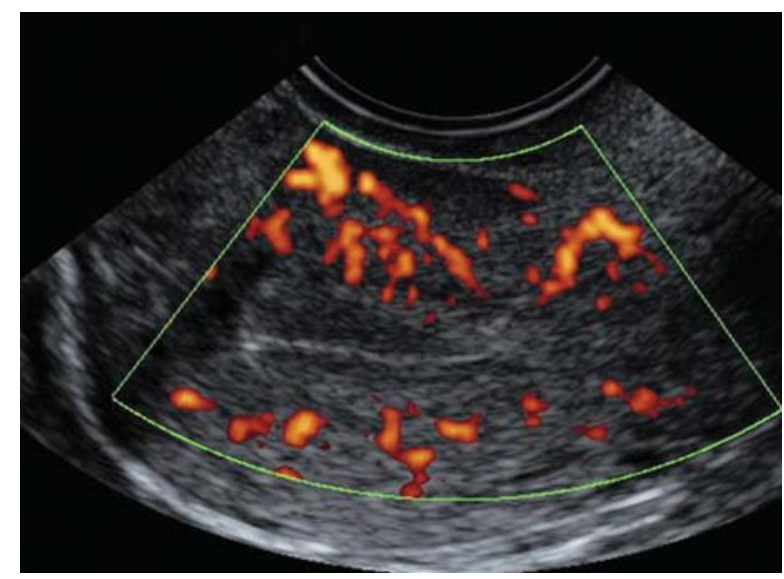

Fig. 5: Endometrial vascularity: Zone 2

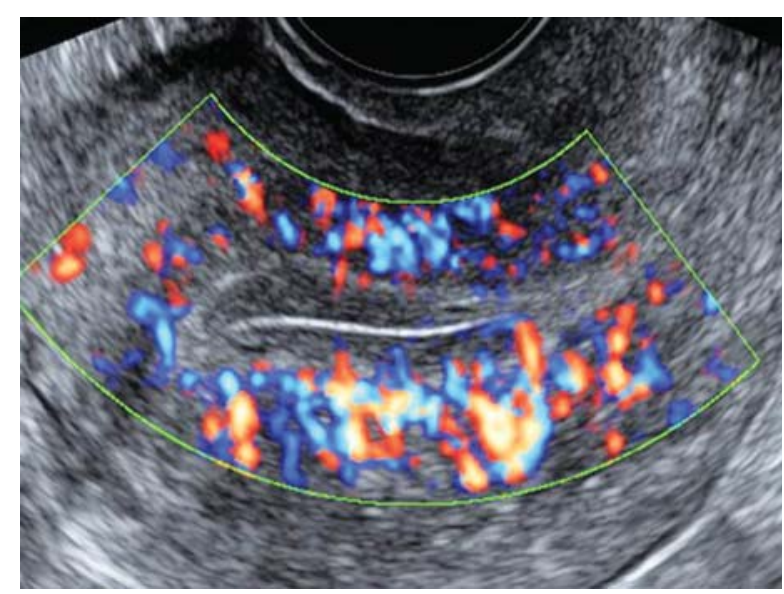

Fig. 6: Endometrial vascularity: Zone 3 


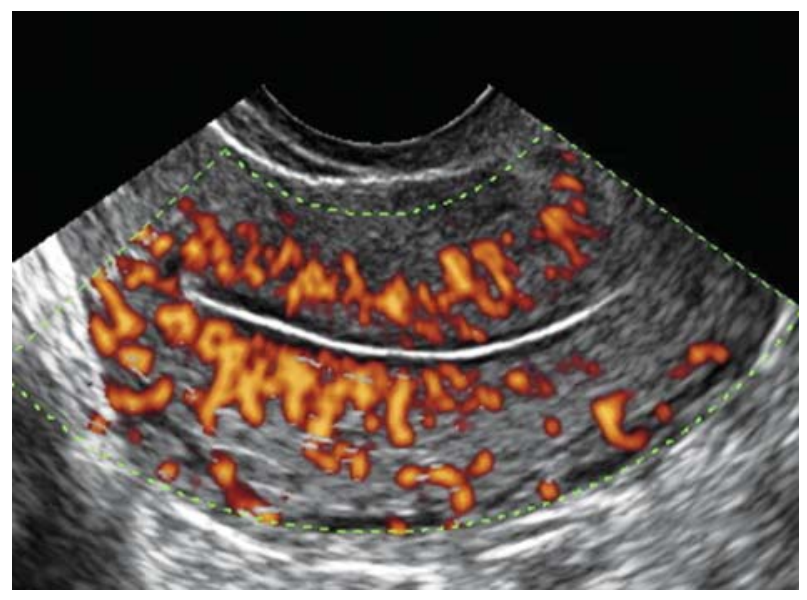

Fig. 7: Endometrial vascularity: Zone 4

But, there are several reports by different groups ${ }^{4}$ that agree on the fact that implantation rates can be more correlated to the vascularity of the endometrium rather than the thickness and morphology of the endometrium.

Segmental uterine artery perfusion demonstrates significant correlation with hormonal and histological markers of uterine receptivity, reaching the highest sensitivity for subendometrial blood flow. ${ }^{5}$ We have in this study, tried to evaluate the pregnancy rates and abortion rates in ovum donation-fresh embryo-transfer cycles, with endometrial vascularity. We have followed Applebaum's zones of vascularity for categorizing endometrial vascularity. The zones of vascularity are defined according to Applebaum ${ }^{2}$ as zone 1 when the vascularity on power Doppler is seen only at endometrium myometrium junction, zone 2 when vessels penetrate through the hyperechogenic endometrial edge, zone 3 when it reaches intervening hypoechogenic zone and zone 4 when they reach the endometrial cavity. Zaidi et al found that absence of flow in the endometrial and subendometrial zones on day of hCG indicate total failure of implantation. ${ }^{4}$ They have shown pregnancy rates related to the zones of vascular penetration:

\begin{tabular}{|c|c|c|c|c|}
\hline Vascularity & Zone 1 & Zone 2 & Zone 3 & Zone 4 \\
\hline No. of patients & 31 & 96 & 269 & 67 \\
\hline$+\beta-\mathrm{hCG}$ & 6 & 21 & 107 & 47 \\
\hline Gest. sac & 3 & 14 & 99 & 46 \\
\hline Abortions & 3 & 5 & 6 & 1 \\
\hline
\end{tabular}

Table 2: The distribution of patient population for vascularity in zones 1, 2, 3 and 4 of the endometrium

\begin{tabular}{lrrrr}
\hline Vascularity & Zone 1 & Zone 2 & Zone 3 & Zone 4 \\
\hline Patients (\%) & 6.69 & 20.73 & 58 & 14.47 \\
$+\beta$-hCG (\%) & 19 & 21.87 & 39.77 & 70.14 \\
Gest. sac (\%) & 9.6 & 14.58 & 36.8 & 68.65 \\
Abortions (\%) & 50 & 23.8 & 5.6 & 1.5 \\
\hline
\end{tabular}

$26.7 \%$ for zone 1, 36.4\% for zone 2 and $37.9 \%$ for zone 3 . One more comparision of two studies have also shown similar results: ${ }^{6}$

\begin{tabular}{lcc} 
- Zone 1 & $3.5-7.5 \%$ & $5.2 \%$ \\
- Zone 2 & $15.8-29.7 \%$ & $28.7 \%$ \\
- Zone 3 & $24.2-47.8 \%$ & $52 \%$ \\
- Zone 4 & $67.3 \%$ & $74 \%$ \\
\hline
\end{tabular}

Our findings are similar to the above-referred studies and would only endorse the fact that endometrial vascularity in zones 3 and 4 is a good predictor for better pregnancy outcomes.

\section{CONCLUSION}

Conception rates were almost double when endometrial vascularity was seen in zone 3 and 4 than when the vascularity in the endometrium reached only zone 1 and 2 . The abortion rates also are considerably high when the vascularity in the endometrium reached only zone 1 and 2 . Therefore we believe that endometrial vascularity is an important parameter to assess the implantation potential of the endometrium.

\section{REFERENCES}

1. Smith B, Porter R, Ahuja K, Craft I, et al. Ultrasonic assessment of endometrial changes in stimulated cycles in an in vitro fertilization and embryo transfer program. J In Vitro Fertil Embryo Transf 1984;1:233-38.

2. Applebaum M. The steel or teflon endometrium-ultrasound visualization of endometrial vascularity in IVF patients and outcome. Presented at The third World Congress of Ultrasound in obstetrics and gyneacology. Ultrasound Obstet Gynecol 1993; 3(Suppl 2):10

3. Gonen Y, Casper RF. Prediction of implantation by sonographic appearance of the endometrium during controlled ovarian stimulation for in vitro fertilization (IVF). J In Vitro Fertil Embryo Transf 1990;7:146-52.

4. Zaidi J, Campbell S, Pittrof R, Tan SL. Endometrial thickness, morphology, vascular penetration and velocimetry in predicting implantation in an in vitro fertilization program. Ultrasound Obstet Gynecol 1995;6:191-98.

5. Kupesic S, Kurjak A. Prediction of IVF outcome by three dimensional ultrasound. Hum Reprod 2002;17:950-55.

6. Chein LW, et al. Assessment of uterine receptivity by the endometrial-subendometrial blood flow distribution pattern in women undergoing IVF-ET. Fertil-Steril 2002;78:245-51.

\section{ABOUT THE AUTHOR}

\section{Chaitanya Nagori (Corresponding Author)}

Consultant, Department of Infertility, Dr Nagori's Institute for Infertility and IVF, Ahmedabad, Gujarat, India, e-mail: cbnagori@yahoo.com

\section{Sonal Panchal}

Consultant, Department of Ultrasound, Dr Nagori’s Institute for Infertility and IVF, Ahmedabad, Gujarat, India 